Article

\title{
Evolution of Dislocation Loops Induced by Different Hydrogen Irradiation Conditions in Reduced-Activation Martensitic Steel
}

\author{
Weiping Zhang ${ }^{1}$, Liping Guo ${ }^{1, *} \mathbb{0}$, Zhenyu Shen ${ }^{1}$, Jingping Xin ${ }^{2}{ }^{\oplus}$, Qunying Huang ${ }^{2}$, \\ Yaxia Wei ${ }^{1}$, Yunxiang Long ${ }^{1}$, Xiong Zhou ${ }^{1}$ and Cheng Chen ${ }^{1}$ \\ 1 Hubei Key Laboratory of Nuclear Solid Physics, Key Laboratory of Artificial Micro- and Nano-structures of \\ Ministry of Education and School of Physics and Technology, Wuhan University, Wuhan 430072, China; \\ zhangweiping@whu.edu.cn (W.Z.); shenzy@whu.edu.cn (Z.S.); weiyx@whu.edu.cn (Y.W.); \\ kobe-long@whu.edu.cn (Y.L.); peter.zhoux@whu.edu.cn (X.Z.); 2016202020013@whu.edu.cn (C.C.) \\ 2 Key Laboratory of Neutronics and Radiation Safety, Institute of Nuclear Energy Safety Technology, \\ Chinese Academy of Sciences, Hefei 230031, Anhui, China; jingping.xin@fds.org.cn (J.X.); \\ qunying.huang@fds.org.cn (Q.H.) \\ * Correspondence: guolp@whu.edu.cn; Tel.: +86-27-6875-2481 (ext. 2223)
}

Received: 8 October 2018; Accepted: 12 November 2018; Published: 14 November 2018

\begin{abstract}
Hydrogen can be induced in various ways into reduced-activation ferritic/martensitic (RAFM) steels when they are used as structural materials for advanced nuclear systems. However, because of the fast diffusion of hydrogen in metals, the effect of hydrogen on the evolution of irradiation-induced defects was almost neglected. In the present work, the effect of hydrogen on the evolution of dislocation loops was investigated using a transmission electron microscope. Specimens of reduced-activation ferritic/martensitic (RAFM) steels were irradiated with hydrogen ions to $5 \times 10^{20} \mathrm{H}^{+} \bullet \mathrm{m}^{-2}$ at $523-823 \mathrm{~K}$, and to $1 \times 10^{20} \mathrm{H}^{+} \bullet \mathrm{m}^{-2}-5 \times 10^{20} \mathrm{H}^{+} \bullet \mathrm{m}^{-2}$ at $723 \mathrm{~K}$. The experimental results reveal that there is an optimum temperature for dislocation loop growth, which is $\sim 723 \mathrm{~K}$, and it is greater than the reported values for neutron irradiations. Surprisingly, the sizes of the loops produced by hydrogen ions, namely, $93 \mathrm{~nm}$ and $286 \mathrm{~nm}$ for the mean and maximum value, respectively, at the peak dose of 0.16 dpa under $723 \mathrm{~K}$, are much larger than that produced by neutrons and heavy ions at the same damage level and temperature. The results indicate that hydrogen could enhance the growth of loops. Moreover, $47.3 \% \frac{1}{2} \mathrm{a}_{0}<111>$ and $52.7 \% \mathrm{a}_{0}<100>$ loops were observed at $523 \mathrm{~K}$, but $\frac{1}{2} \mathrm{a}_{0}<111>$ loops disappeared and only $\mathrm{a}_{0}<100>$ loops existed above $623 \mathrm{~K}$. Compared with the neutron and ion irradiations, the presence of hydrogen promoted the formation of $\mathrm{a}_{0}<100>$ loops.
\end{abstract}

Keywords: dislocation loops; hydrogen ion irradiation; transmission electron microscope (TEM); reduced-activation ferritic/martensitic steels

\section{Introduction}

A challenge for developing advanced nuclear systems, such as fusion reactors, Generation IV fission reactors, and accelerator-driven spallation (ADS) devices, is the deep understanding of the complicated irradiation damage mechanisms in irradiation resistant materials [1-4]. Reduced-activation ferritic/martensitic (RAFM) steels are considered as prime candidate structural materials for advanced nuclear systems, owing to their excellent mechanical properties, microstructural stability, and irradiation resistance [5-7]. However, the properties of the RAFM steels will degrade when they are exposed to conditions of high energy neutron irradiations, such as $14 \mathrm{MeV}$ for fusion reactors and hundreds of $\mathrm{MeV}$ for ADS devices. In such conditions, hydrogen and helium are 
introduced via nuclear transmutation reactions of $(n, p)$ and $(n, \alpha)$, which cause the degradations to be accelerated [8-11]. The production rate of hydrogen is 30-40 appm/dpa in fusion reactors and $1500 \mathrm{appm} / \mathrm{dpa}$ in ADS devices. Hydrogen can also be introduced by fuel permeation and diffusion with a high concentration in fission and fusion reactors. In previous studies, there has been considerable experience in experimentation and modeling regarding the role that helium plays in the accelerated degradations of materials [12-14], but there has been little for hydrogen. Because the diffusion of hydrogen is fast, it was generally understood that hydrogen would diffuse out of steels, and that it had little effect on microstructure evolution, especially at elevated temperatures [4].

Actually, hydrogen played an important role in the microstructure evolution. Kupriiyanova et al. found that the co-implantation of hydrogen resulted in more swelling than heavy-ion implantation alone [7]. In RAFM steels, there are some studies concerning the role of hydrogen in microstructures, most of which are focused on bubbles $[9,15]$, whilst there are few studies on dislocation loops. However, the dislocation loop is a type of nanoscale crystal defect that is the most easily produced by irradiation. Some experimental results have suggested that irradiation hardening mainly originates from the presence of dislocation loops [16]. Therefore, it is significant to investigate the evolution of loops induced by hydrogen irradiation. In the present study, we investigate the evolution of loops induced by hydrogen ion irradiation at different conditions (fluence from $1 \times 10^{20}$ to $5 \times 10^{20} \mathrm{H}^{+} \bullet \mathrm{m}^{-2}$, and temperature from 523 to $823 \mathrm{~K}$ ) in RAFM steels via transmission electron microscope (TEM) observation.

\section{Materials and Methods}

The composition of the steel used in present study was Fe $9.24 \mathrm{wt} \%, \mathrm{Cr} 2.29 \mathrm{wt} \%$, W $0.49 \mathrm{wt} \%$, Mn $0.25 \mathrm{wt} \%, \mathrm{~V} 0.25 \mathrm{wt} \%$, Si $0.088 \mathrm{wt} \%$, and C $0.0059 \mathrm{wt} \% \mathrm{P}$. The details of the heat treatment and fabrication are reported in the literature [17]. The material was cut into sheets with a thickness of $0.5 \mathrm{~mm}$. The sheets were mechanically polished to the thickness of $0.1 \mathrm{~mm}$, from both sides. Disks with diameter of $3 \mathrm{~mm}$ were punched out from the sheets, and were then finally milled to a thickness of about $50 \mu \mathrm{m}$. The perforation thin foils for the TEM observation were done by twin-jet electro-polishing, using a solution of $5 \%$ perchloric acid and $95 \%$ ethanol electrolyte at $243 \mathrm{~K}$.

One part of the specimens (prepared TEM foils) was irradiated by $10 \mathrm{keV} \mathrm{H}^{+}$to $5 \times 10^{20} \mathrm{H}^{+} \bullet \mathrm{m}^{-2}$ at $523 \mathrm{~K}, 623 \mathrm{~K}, 723 \mathrm{~K}$, and $823 \mathrm{~K}$, respectively. At the temperature of $723 \mathrm{~K}$, the other part of the specimens was irradiated by $10 \mathrm{keV} \mathrm{H} \mathrm{H}^{+}$to $1 \times 10^{20} \mathrm{H}^{+} \bullet \mathrm{m}^{-2}, 2 \times 10^{20} \mathrm{H}^{+} \bullet \mathrm{m}^{-2}, 3 \times 10^{20} \mathrm{H}^{+} \bullet \mathrm{m}^{-2}$, and $5 \times 10^{20} \mathrm{H}^{+} \bullet \mathrm{m}^{-2}$, corresponding to the peak damage dose of $0.03 \mathrm{dpa}, 0.06 \mathrm{dpa}, 0.10 \mathrm{dpa}$, and $0.16 \mathrm{dpa}$, respectively. Figure 1 shows the atom concentration and damage dose profiles calculated using SRIM2008, with a displacement energy of $40 \mathrm{eV}$ [18]. The irradiations were conducted using the ion implanter from the Accelerator Lab of Wuhan University. The observations of the microstructures were conducted using a JEM-2010HT TEM (JEOL, the Center for Electron Microscopy in Wuhan University, China) operated at $200 \mathrm{kV}$. The thickness $(\sim 120 \mathrm{~nm})$ of the specimens at the observed area were estimated by counting the number of thickness fringes from the edge of the thin foil.
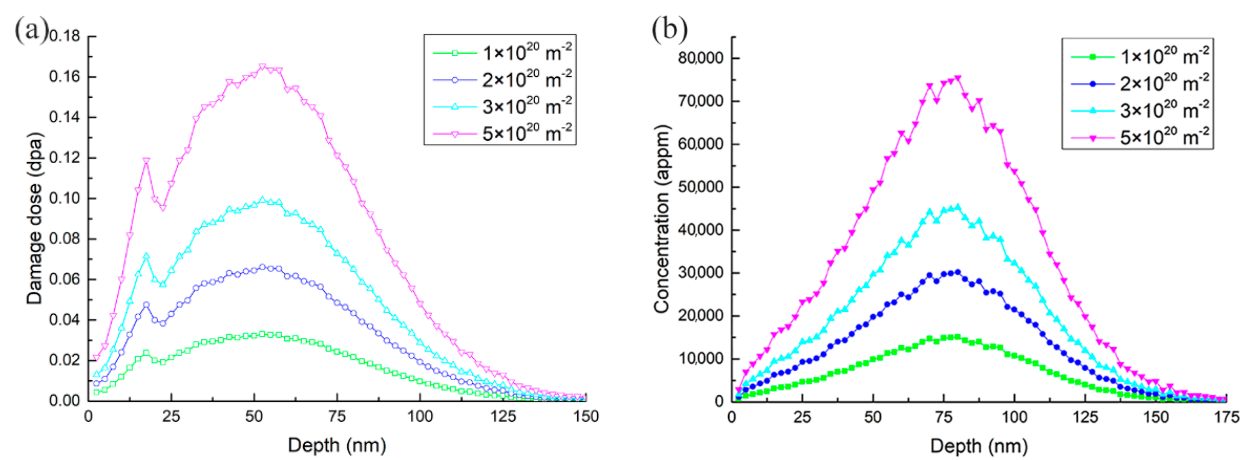

Figure 1. SRIM calculations of depth profiles of (a) damage events and (b) hydrogen concentrations in the specimen, irradiated using $10 \mathrm{keV} \mathrm{H} \mathrm{H}^{+}$to $1 \times 10^{20} \mathrm{H}^{+} \bullet \mathrm{m}^{-2}, 2 \times 10^{20} \mathrm{H}^{+} \bullet \mathrm{m}^{-2}, 3 \times 10^{20} \mathrm{H}^{+} \bullet \mathrm{m}^{-2}$, and $5 \times 10^{20} \mathrm{H}^{+} \bullet \mathrm{m}^{-2}$. 


\section{Results}

\subsection{Dislocation Loop Evolution in RAFM Steel with Increasing Temperature}

In all of the specimens, no bubbles or cavities were observed by TEM. As shown in Figure 2, interstitial dislocation loops were observed after the hydrogen irradiation to $5 \times 10^{20} \mathrm{H}^{+} \bullet \mathrm{m}^{-2}$ (0.16 dpa), at temperatures ranging from $523 \mathrm{~K}$ to $823 \mathrm{~K}$. In Figure 2a, many small loops, with an average size of $6.6 \mathrm{~nm}$ and density of $2.5 \times 10^{21} \mathrm{~m}^{-3}$ (operating diffraction vector $(\mathrm{g})=110$ ), were observed after irradiation at $523 \mathrm{~K}$. The Burgers vectors of these dislocation loops were either $\frac{1}{2} \mathrm{a}_{0}<111>$ or $\mathrm{a}_{0}<100>$. The densities of two types of loops were evaluated using the following equations that were derived using the invisibility criteria listed in Table 1:

$$
\begin{gathered}
\frac{2}{3} \rho_{\mathbf{b}=a_{0}<100>}+\frac{1}{2} \rho_{b=\frac{1}{2} a_{0}<111>}=\rho_{\mathbf{g}=0-11}, \\
\frac{1}{3} \rho_{\mathbf{b}=a_{0}<100>}+\rho_{\mathbf{b}=\frac{1}{2} a_{0}<111>}=\rho_{\mathbf{g}=-200}
\end{gathered}
$$

$\rho_{\mathbf{g}}$ is the number density of the visible dislocation loops at the different diffraction vector. $\rho_{\mathbf{b}}$ is the number density of the dislocation loops that have the Burgers vector, $\mathbf{b}=\frac{1}{2} \mathrm{a}_{0}<111>$ or $\mathrm{a}_{0}<100>$. There is an initial approximation that the densities of the loops with all of the possible Burgers vectors with the same family are equal. The density of the loops at the diffraction vectors of $\mathbf{g}=-200$ and $\mathbf{g}=0-11$ is $\rho_{\mathbf{g}=0-11}=2.5 \times 10^{21} \mathrm{~m}^{-3}$ and $\rho_{\mathbf{g}=-200}=2.76 \times 10^{21} \mathrm{~m}^{-3}$, respectively. Then, the solution of the equations is $\rho_{\mathbf{b}=\frac{1}{2} \mathbf{a}_{0}<111>}=2.01 \times 10^{21} \mathrm{~m}^{-3}$ and $\rho_{\mathbf{b}=\mathbf{a}_{0}<100>}=2.24 \times 10^{21} \mathrm{~m}^{-3}$. The relative proportions of the loops with the Burgers vectors of $\frac{1}{2} \mathrm{a}_{0}<111>$ and $\mathrm{a}_{0}<100>$ are $47.3 \%$ and $52.7 \%$, respectively.
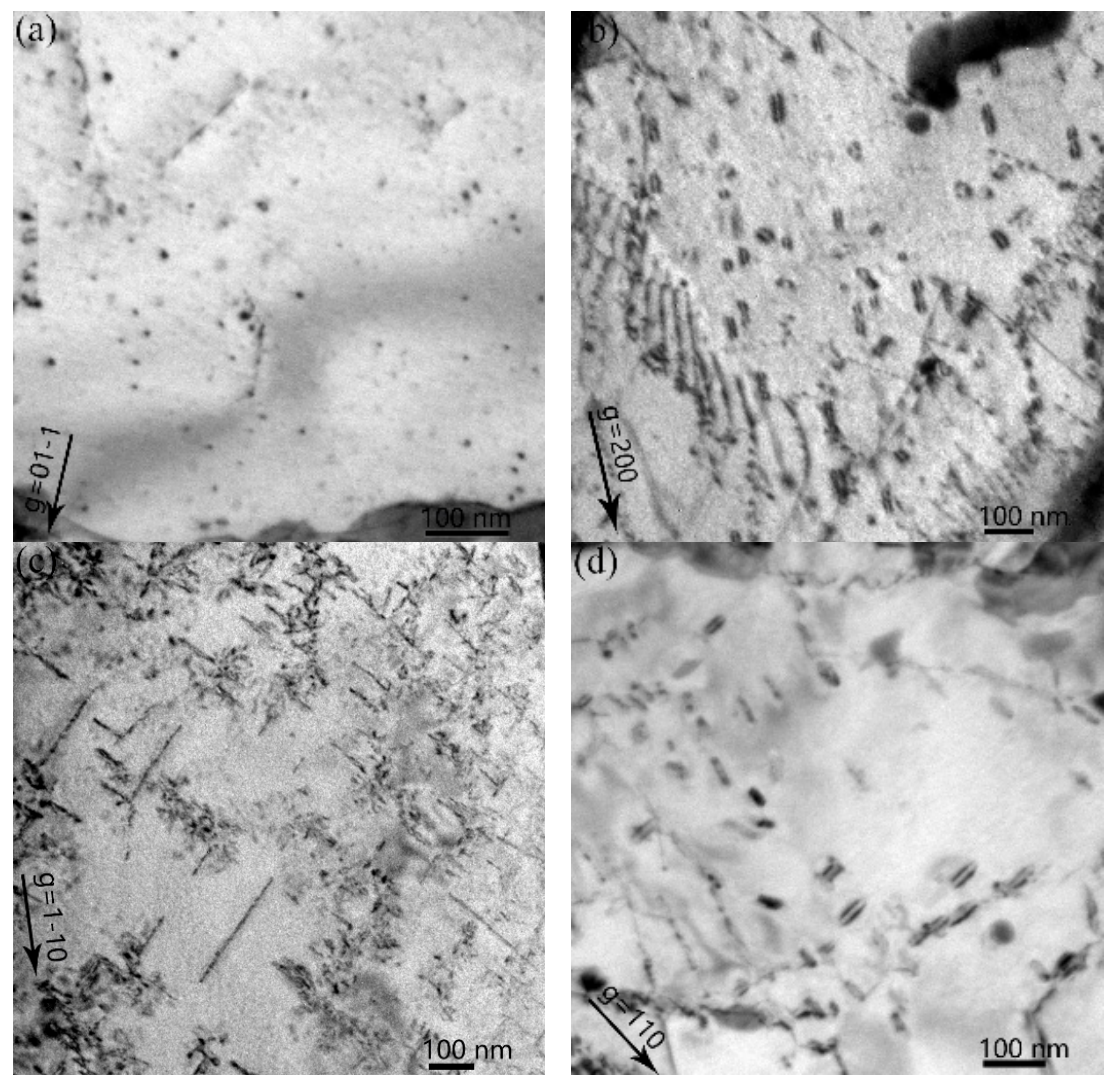

Figure 2. TEM bright field micrographs of specimens irradiated with $\mathrm{H}^{+}$to the fluence of $5 \times 10^{20} \mathrm{H}^{+} \bullet \mathrm{m}^{-2}$ at elevated temperature ((a) $523 \mathrm{~K}, \mathbf{g}=01-1$ near the pole [011]; (b) $623 \mathrm{~K}, \mathbf{g}=200$ near the pole [001]; (c) $723 \mathrm{~K}, \mathbf{g}=1-10$ near the pole [001]; (d) $823 \mathrm{~K}, \mathbf{g}=110$ near the pole [001]). 
Table 1. The invisibility criteria for dislocation loops in TEM observation.

\begin{tabular}{ccccccccc}
\hline $\mathbf{g} \backslash \mathbf{b}$ & $\mathbf{1 1 1}$ & $\mathbf{1 1 - 1}$ & $\mathbf{1 - 1 1}$ & $\mathbf{- 1 1 1}$ & $\mathbf{1 0 0}$ & $\mathbf{0 1 0}$ & $\mathbf{0 0 1}$ \\
\hline $0-11$ & $\times$ & $\sqrt{ }$ & $\sqrt{ }$ & $\times$ & $\times$ & $\sqrt{ }$ & $\sqrt{ }$ \\
-200 & $\sqrt{ }$ & $\sqrt{ }$ & $\sqrt{ }$ & $\sqrt{ }$ & $\sqrt{ }$ & $\times$ & $\times$ \\
-110 & $\times$ & $\times$ & $\sqrt{ }$ & $\sqrt{ }$ & $\sqrt{ }$ & $\sqrt{ }$ & $\times$ \\
020 & $\sqrt{ }$ & $\sqrt{ }$ & $\sqrt{ }$ & $\sqrt{ }$ & $\times$ & $\sqrt{ }$ & $\times$ \\
110 & $\sqrt{ }$ & $\sqrt{ }$ & $\times$ & $\times$ & $\sqrt{ }$ & $\sqrt{ }$ & $\times$ \\
Note: $\mathbf{g}$ is the operating diffraction vector, $\mathbf{b}$ is the Burgers vector; " $\sqrt{ }$ " is visible; " $\times$ " is invisible.
\end{tabular}

In Figure 2b, when the temperature increased to $623 \mathrm{~K}$, larger loops with an average size of $34.0 \mathrm{~nm}$ and density of $1.1 \times 10^{21} \mathrm{~m}^{-3}(\mathrm{~g}=110)$ were observed. When irradiated at $723 \mathrm{~K}$, loops with an average size of $93.6 \mathrm{~nm}$ and density of $1.7 \times 10^{21} \mathrm{~m}^{-3}(\mathrm{~g}=1-10)$ were observed. Among all of the irradiation temperatures, the loops had the largest average size at $723 \mathrm{~K}$. However, the dislocation loops with a mean size of $36.0 \mathrm{~nm}$ and a number density of $7.9 \times 10^{20} \mathrm{~m}^{-3}(\mathrm{~g}=110)$ became smaller at a temperature of $823 \mathrm{~K}$. At $623-823 \mathrm{~K}$, all of the loops had the Burgers vectors of $\mathbf{b}=\mathrm{a}_{0}<100>$.

\subsection{Dislocation Loop Evolution in RAFM Steel with Increasing Hydrogen Fluence}

Figure 3 shows the micrographs of the dislocation loops after hydrogen irradiation at $1 \times 10^{20} \mathrm{H}^{+} \bullet \mathrm{m}^{-2}(0.03 \mathrm{dpa})$ to $5 \times 10^{20} \mathrm{H}^{+} \bullet \mathrm{m}^{-2}(0.16 \mathrm{dpa})$, at a temperature of $723 \mathrm{~K}$. At $1 \times 10^{20} \mathrm{H}^{+} \bullet \mathrm{m}^{-2}$, no dislocation loops were observed in the specimens. However, when the irradiation fluence increased to $2 \times 10^{20} \mathrm{H}^{+} \bullet \mathrm{m}^{-2}$, small loops with a mean size of $4.3 \mathrm{~nm}$ and density of $6.6 \times 10^{22} \mathrm{~m}^{-3}(\mathrm{~g}=110)$ were observed. When the irradiation fluence was further increased from $3 \times 10^{20} \mathrm{H}^{+} \bullet \mathrm{m}^{-2}$ to $5 \times 10^{20} \mathrm{H}^{+} \bullet \mathrm{m}^{-2}$, the average size and density of the loops increased from $22.9 \mathrm{~nm}$ to $93.6 \mathrm{~nm}$ and $8.1 \times 10^{21} \mathrm{~m}^{-3}$ to $1.7 \times 10^{21} \mathrm{~m}^{-3}(\mathrm{~g}=110)$, respectively. At $723 \mathrm{~K}$, all of the loops were determined to be $\mathbf{b}=\mathrm{a}_{0}<100>$.
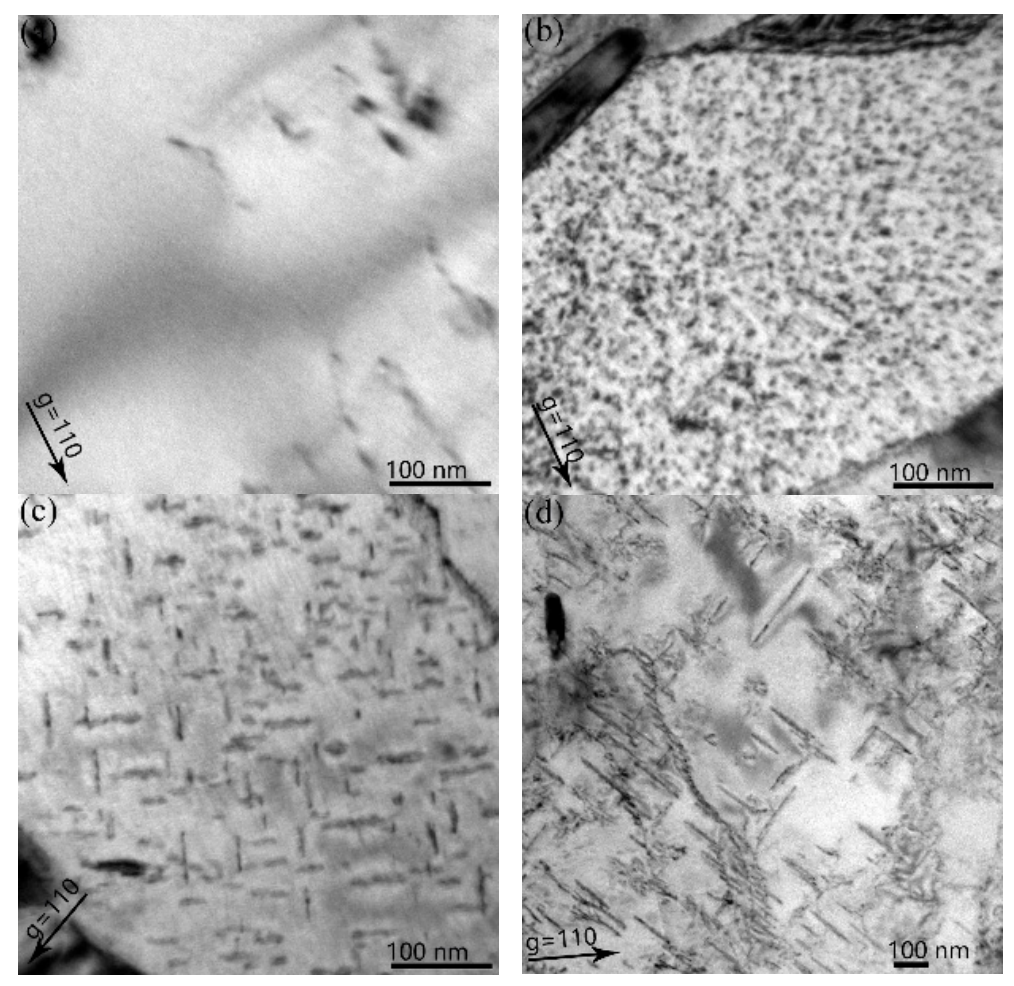

Figure 3. TEM bright field micrographs of specimens irradiated with $\mathrm{H}^{+}$of different fluences at $723 \mathrm{~K}$ ((a) $1 \times 10^{20} \mathrm{H}^{+} \bullet \mathrm{m}^{-2}$; (b) $2 \times 10^{20} \mathrm{H}^{+} \bullet \mathrm{m}^{-2}$; (c) $3 \times 10^{20} \mathrm{H}^{+} \bullet \mathrm{m}^{-2}$; (d) $\left.5 \times 10^{20} \mathrm{H}^{+} \bullet \mathrm{m}^{-2}\right)$. All of the micrographs were observed at $\mathbf{g}=110$ near the pole [001]. 


\subsection{Burgers Vectors Analysis of Dislocation Loops}

The Burgers vectors of the loops were determined using the invisibility criterion of $\mathbf{g} \cdot \mathbf{b}=0$. Figure 4 shows the micrographs of the same area of the specimen irradiated to $5 \times 10^{20} \mathrm{H}^{+} \bullet \mathrm{m}^{-2}$ at $523 \mathrm{~K}$. The same area of the specimen was captured using $\mathbf{g}=01-1$ and -200 near the pole of [011]. The dislocation loops of family A are present on the $\mathbf{g}$ of both -200 and $01-1$. However, the family B loops are only present on the $\mathbf{g}=01-1$. Therefore, the family A loops were determined to be $\mathbf{b}=\frac{1}{2} \mathrm{a}_{0}<111>$, and the family $\mathrm{B}$ loops were $\mathbf{b}=\mathrm{a}_{0}<100>$ (Table 1 ). The dislocation loops in the other specimens were also determined. However, the specimens of the same area were captured using $\mathbf{g}=200,-110,020$, and 110, close to the pole [001]. Figure 5 shows an example of the Burgers vector analyses of the dislocation loops irradiated at $3 \times 10^{20} \mathrm{H}^{+} \bullet \mathrm{m}^{-2}$ at a temperature of $723 \mathrm{~K}$. From these four micrographs, it is clear that there are two families of dislocation loops, $C_{1}$ and $C_{2}$. Family $C_{1}$ is only absent in $\mathbf{g}=020$ and $C_{2}$ is only absent in $\mathbf{g}=200$. Therefore, from the Table 1 , both the family $C_{1}$ and $\mathrm{C}_{2}$ loops were determined to be $\mathrm{a}_{0}<100>$.
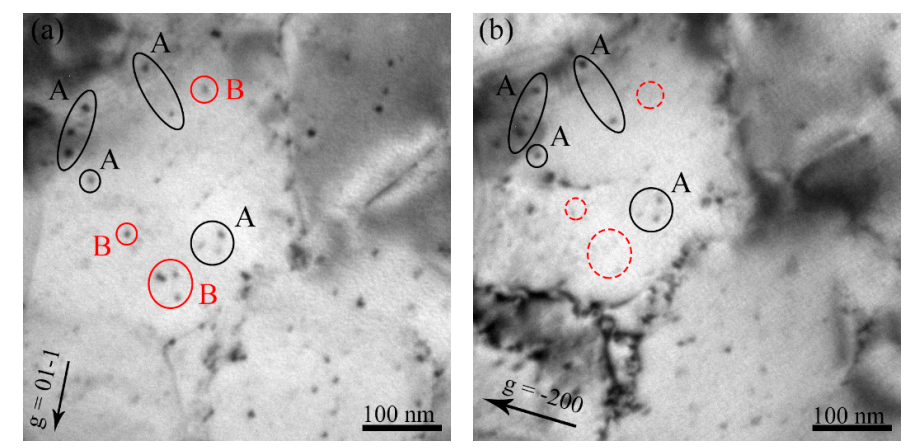

Figure 4. TEM bright field micrographs of dislocation loops in the specimen irradiated to $5 \times 10^{20} \mathrm{H}^{+} \bullet \mathrm{m}^{-2}$ at $523 \mathrm{~K}$. (a) $\mathbf{g}=01-1$, (b) $\mathbf{g}=-200$ near the pole [011]. The Burgers vector of family A loops is $\mathbf{b}=\frac{1}{2} \mathrm{a}_{0}<111>$, which of family $\mathrm{B}$ loops is $\mathbf{b}=\mathrm{a}_{0}<100>$.
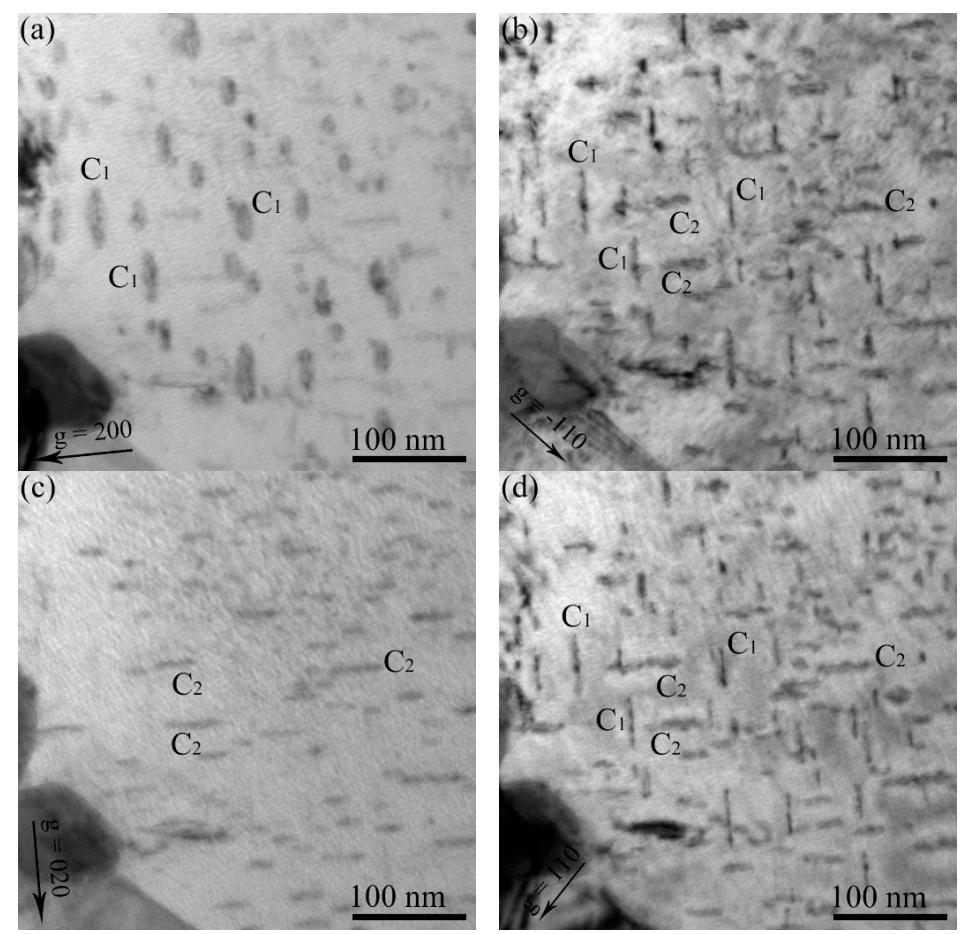

Figure 5. TEM bright field micrographs of dislocation loops in the specimen irradiated at $3 \times 10^{20} \mathrm{H}^{+} \bullet \mathrm{m}^{-2}$ at $723 \mathrm{~K}$. (a) $\mathbf{g}=200,(\mathbf{b}) \mathbf{g}=-110$, (c) $\mathbf{g}=020$, and (d) $\mathbf{g}=110$ near the pole [001]. The Burgers vector of family $C_{1}$ loops is $\mathbf{b}=\mathrm{a}_{0}<100>$, and the family of $C_{2}$ loops is $\mathbf{b}=\mathrm{a}_{0}<010>$. 


\section{Discussion}

\subsection{Evolution of Dislocation Loops Dependent on Irradiation Temperature}

Figure 6 summarizes the evolutions of the loops dependent on the irradiation temperature and fluence, while Figure 7 shows the size distributions of the loops. As shown in Figure 6a, both the size curve and the density curve have a peak at a temperature of $723 \mathrm{~K}$, respectively. This reveals that there is an optimum temperature for dislocation loop growth and nucleation. However, at a low temperature of $523 \mathrm{~K}$, the dislocation loops have the largest number density. This is mostly due to the fact that the diffusion coefficient, D, of the defect (interstitial atom and vacancy) is a function of temperature, as follows:

$$
D=D_{0} \exp \left(\frac{-\mathrm{Q}}{\mathrm{kT}}\right),
$$

where $\mathrm{D}$ is the diffusion coefficient of the defect, $\mathrm{D}_{0}$ is a pre-factor that is independent of temperature, $\mathrm{Q}$ is the activation energy for the migration of the defect, $\mathrm{k}$ is the Boltzmann's constant, and $\mathrm{T}$ is temperature. At a low temperature, the diffusion coefficient of the interstitial clusters is small. Thus, the nucleated dislocation loops are hard to migrate, and they combine with each other to grow up. At this stage, the nucleation of the dislocation loops is dominant. With the increase of temperature, the diffusion coefficient of the interstitial clusters increases, so that the dislocation loops can combine with each other to grow up, while the resulting density of the dislocation loop decreases. At $723 \mathrm{~K}$, the nucleation rate and growth rate of the loops reach maximums. But as the temperature is further increased successively, the average size and density of the loops are both decreased. This is ascribed to the fact that vacancy clusters became more mobile. The vacancy has a larger activation energy for migration compared with interstitial atoms. The research of Ehrhart et al. found that the interstitial atoms start to migrate at temperatures below $300 \mathrm{~K}$, but the temperature for the vacancy is above $450 \mathrm{~K}$ in pure copper [19]. Therefore, at a high temperature, when the vacancy cluster becomes more mobile, the likelihood of the recombination of vacancy clusters and interstitial clusters will increase. Thus, the average size and number density of the dislocation loops will decrease when the temperature is high enough.
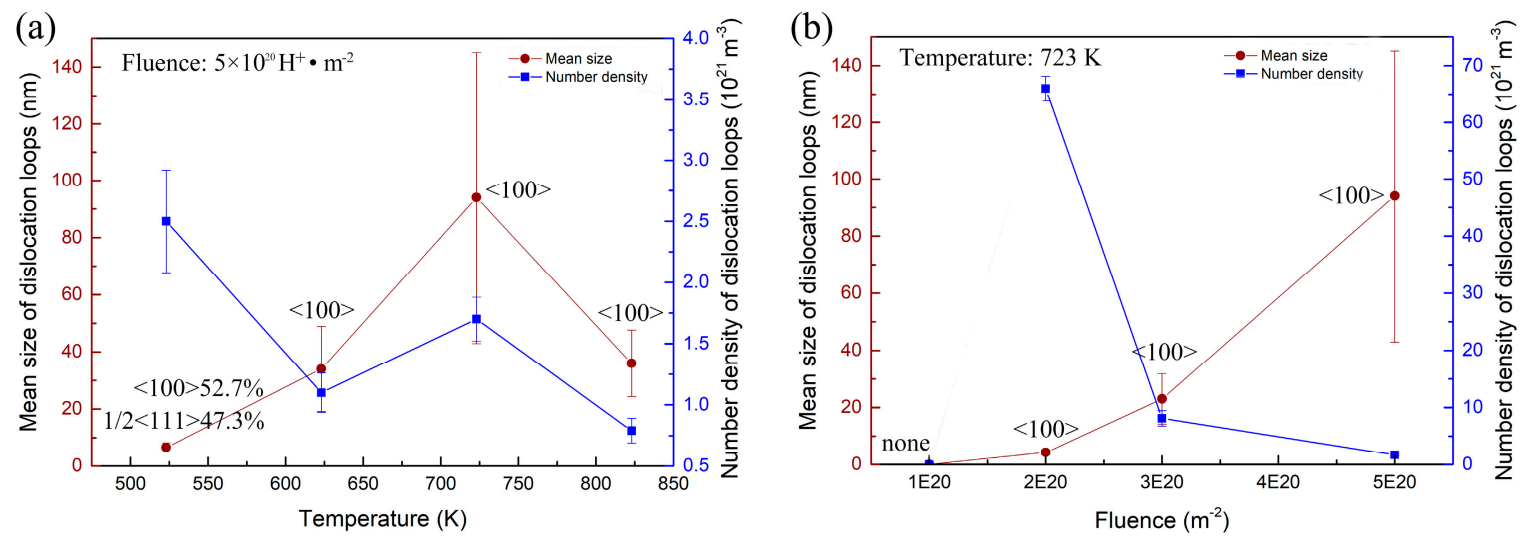

Figure 6. Mean sizes and densities of dislocation loops dependent on irradiation (a) temperature and (b) fluence. The meaning of the vertical lines is standard deviation. 


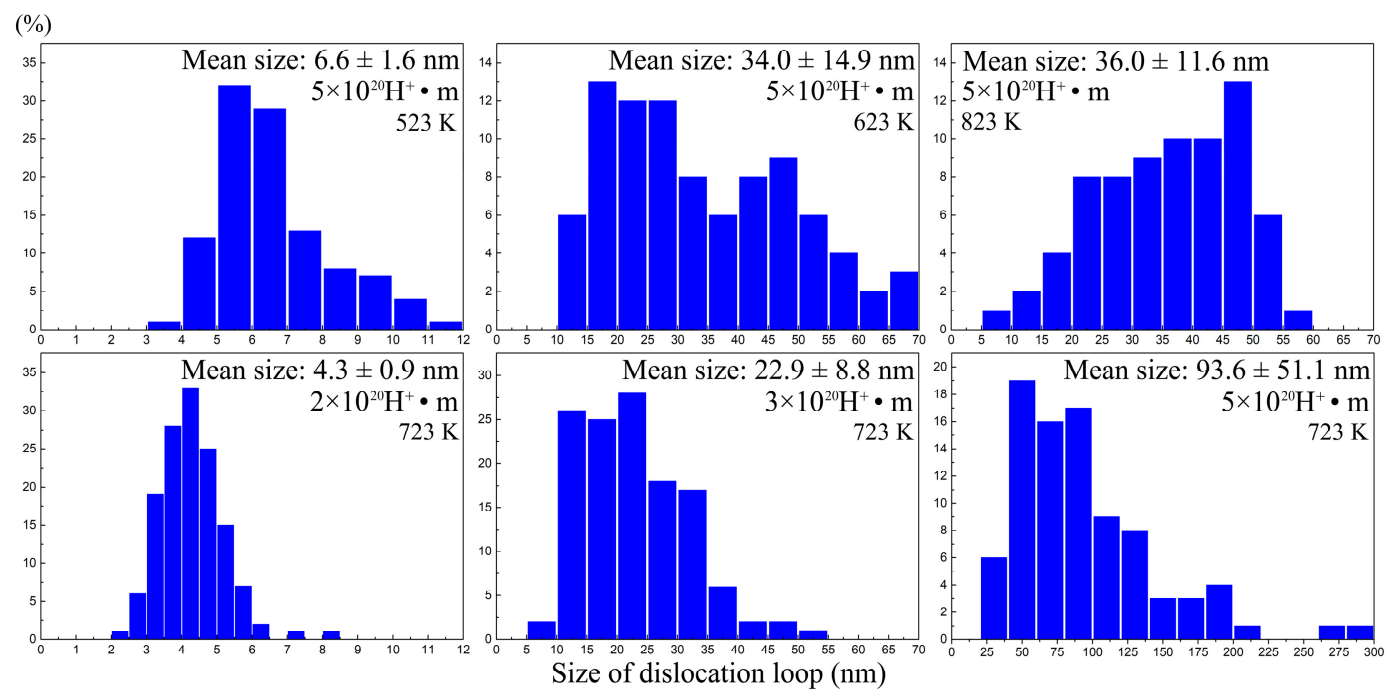

Figure 7. The size distributions of the dislocation loops in all of the specimens. Below each value of the mean size, the corresponding standard deviation is added.

In previous studies, many researchers investigated the relationships between the size and density of dislocation loops and temperature. For example, Klimenkov et al. studied Eurofer-97 irradiated with neutrons at $16.3 \mathrm{dpa}$, at a temperature of $523 \mathrm{~K}-723 \mathrm{~K}$. They found that the peak position of the size curve and density curve is at $623 \mathrm{~K}$ and $573 \mathrm{~K}$, respectively [20]. In the present study, the correspondent peak temperature is $723 \mathrm{~K}$, which is greater than the results reported in the above literature. On one hand, these differences might be ascribed to the different chemical components of steel, because different types and quantities of solute atoms may change the diffusion coefficient of the defects, and hence change their mobility and recombination. On the other hand, the presence of hydrogen can also significantly change the mobility of the defects, especially for a vacancy. For instance, the migration barrier of a vacancy in $\alpha$-Fe is $0.64 \mathrm{eV}$ and will be increased to $0.76 \mathrm{eV}$ when the hydrogen is trapped [21]. For F82H, a RAFM steel whose chemical composition is close to the steel that was used in the present study, the migration energy of a vacancy increases from 1.2-1.3 eV to $1.3-1.4 \mathrm{eV}$ after 20 appm of hydrogen is added [22]. This means that upon the presence of hydrogen, a higher temperature is needed for the migration of the vacancy, and hence the recombination of the vacancy with loops. Therefore, the size of the loops shall start to reduce at higher temperatures (i.e., the peak position of the size distribution of dislocation loops with temperature should shift towards higher temperature, just as our experimental results have shown).

\subsection{Evolution of Dislocation Loop Dependent on Irradiation Fluence}

As shown in Figure $6 \mathrm{~b}$, with the increasing irradiation fluence of hydrogen, the mean size of the dislocation loops increased, but the number density decreased. This is a universal rule for the dislocation loop evolution dependence of irradiation fluence. What is notable is that the average size of the loops has grown to $93.6 \mathrm{~nm}$ and the maximum size is $285.7 \mathrm{~nm}$ at a temperature of $723 \mathrm{~K}$. However, the peak damage dose is only $0.16 \mathrm{dpa}$, but the peak hydrogen atom concentration is as high as 75,500 appm. Previous studies have investigated the evolution of loops in body-centered cubic (bcc) iron and iron-chrome alloys with irradiations of neutron and heavy ion, which is summarized in Table 2 [23-33]. Compared to neutron and heavy ion, we find that hydrogen ion irradiations produce larger dislocation loops at the same damage level. For example, in the literature [28], the average size of the loops is $2.2 \mathrm{~nm}$ in $\mathrm{F} 82 \mathrm{H}$ with the irradiation of neutrons to $0.7 \mathrm{dpa}$ at a temperature of $523 \mathrm{~K}$. The mean size of the dislocation loop caused by hydrogen irradiation is $6.6 \mathrm{~nm}(0.16 \mathrm{dpa})$ at $523 \mathrm{~K}$ in the present study, which is much larger than the loops caused by neutron irradiations. This result might be attributed to a high hydrogen concentration in the specimen, because no hydrogen is induced 
in heavy ion irradiation, and a low hydrogen concentration is induced in the neutron irradiation through the (n, p) transmutation reaction (fission neutron source), while in the present study, a high concentration of hydrogen is implanted into the specimens.

Table 2. Summary of dislocation loops in pure iron and iron-based alloys under the irradiations of $\mathrm{Fe}^{+}$ and neutrons, as well as the present experimental results.

\begin{tabular}{|c|c|c|c|c|c|c|c|c|c|c|}
\hline \multirow{2}{*}{ Materials } & \multirow{2}{*}{$\begin{array}{l}\text { Irradiation } \\
\text { Type }\end{array}$} & \multirow{2}{*}{$\begin{array}{l}\text { Tirr } \\
\text { (K) }\end{array}$} & \multirow{2}{*}{$\begin{array}{l}\text { Tirr } \\
\left({ }^{\circ} \mathrm{C}\right)\end{array}$} & \multirow{2}{*}{$\begin{array}{l}\text { Dose } \\
\text { (dpa) }\end{array}$} & \multicolumn{2}{|c|}{ Loop Size (nm) } & \multirow{2}{*}{$\begin{array}{l}\text { Density } \\
\left(\mathrm{m}^{-3}\right)\end{array}$} & \multicolumn{2}{|c|}{$\begin{array}{l}\text { Burgers Vectors } \\
\text { of Loop }\end{array}$} & \multirow{2}{*}{ Ref. } \\
\hline & & & & & Max & Mean & & $\begin{array}{l}1 / 2 a_{0} \\
<111>\end{array}$ & $\begin{array}{c}a_{0} \\
<100>\end{array}$ & \\
\hline \multirow[t]{6}{*}{ Pure Fe } & Ion $(\mathrm{Fe}+)$ & 573 & 300 & 1 & - & $5-20$ & - & $92 \%$ & $8 \%$ & [23] \\
\hline & & 673 & 400 & 1.3 & 68 & $30-50$ & - & $\sqrt{ }$ & $\sqrt{ }$ & [24] \\
\hline & & 723 & 450 & 2 & 225 & - & - & $\sqrt{ }$ & $\sqrt{ }$ & [24] \\
\hline & & 773 & 500 & 2 & 50 & - & - & $x$ & $\sqrt{ }$ & [24] \\
\hline & & & & 2.5 & 85 & - & - & $x$ & $\sqrt{ }$ & [25] \\
\hline & & 823 & 550 & 74.2 & - & 100-150 & - & $x$ & $\sqrt{ }$ & [26] \\
\hline \multirow[t]{4}{*}{ CLAM } & Ion $(\mathrm{Fe}+)$ & 573 & 300 & 0.46 & 8.5 & - & $1.9 \times 10^{22}$ & - & - & [27] \\
\hline & & & & 2.79 & 13 & - & $2.8 \times 10^{22}$ & - & - & [27] \\
\hline & & 823 & 550 & 0.38 & 18 & - & $9.4 \times 10^{21}$ & - & - & [27] \\
\hline & & & & 2.75 & 32 & - & $1.5 \times 10^{22}$ & - & - & {$[27]$} \\
\hline \multirow[t]{6}{*}{$\mathrm{F} 82 \mathrm{H}$} & Neutron & 523 & 250 & 0.7 & - & 2.2 & $3 \times 10^{21}$ & - & - & [28] \\
\hline & & & & 2.8 & - & 7.9 & $1.4 \times 10^{22}$ & $\sqrt{ }$ & $x$ & [29] \\
\hline & & 573 & 300 & 51 & - & 11 & $4 \times 10^{22}$ & $\sqrt{ }$ & $x$ & [29] \\
\hline & & 575 & 302 & 8.8 & - & 5.4 & - & $\sqrt{ }$ & $\sqrt{ }$ & [30] \\
\hline & & 583 & 310 & 6.9 & - & 6.9 & $2.8 \times 10^{22}$ & - & - & [28] \\
\hline & & 673 & 400 & 7.4 & - & 33 & $6 \times 10^{21}$ & - & - & [29] \\
\hline Eurofer-97 & Neutron & 573 & 300 & 15 & - & $2.8-4.2$ & $2.1-5.8 \times 10^{21}$ & $\sqrt{ }$ & $\sqrt{ }$ & [31] \\
\hline \multirow[t]{3}{*}{ T91 } & Neutron & 403 & 130 & 4.6 & - & 3.8 & $2.5 \times 10^{22}$ & - & - & [32] \\
\hline & & 523 & 250 & 8.3 & - & 4.5 & $3.6 \times 10^{22}$ & - & - & [32] \\
\hline & & 633 & 360 & 11.8 & - & 8.9 & $1.3 \times 10^{22}$ & - & - & [32] \\
\hline \multirow[t]{2}{*}{ FV448 } & Neutron & 653 & 380 & 30 & 110 & 50 & $7 \times 10^{21}$ & - & $>98 \%$ & [33] \\
\hline & & 733 & 460 & 30 & $>300$ & 300 & $1 \times 10^{18}$ & - & $>98 \%$ & [33] \\
\hline \multirow[t]{6}{*}{$\mathrm{Fe}-9.24 \mathrm{Cr}$} & Ion $(\mathrm{H}+)$ & 523 & 250 & 0.16 & 11.7 & 6.6 & $2.5 \times 10^{21}$ & $47.3 \%$ & $52.7 \%$ & $\begin{array}{l}\text { Present } \\
\text { study }\end{array}$ \\
\hline & & 623 & 350 & 0.16 & 68.9 & 34.0 & $1.1 \times 10^{21}$ & $x$ & $\sqrt{ }$ & \\
\hline & & 723 & 450 & 0.06 & 8.1 & 4.3 & $6.6 \times 10^{22}$ & $x$ & $\sqrt{ }$ & \\
\hline & & & & 0.1 & 52.7 & 22.9 & $8.1 \times 10^{21}$ & $x$ & $\sqrt{ }$ & \\
\hline & & & & 0.16 & 285.7 & 93.6 & $1.7 \times 10^{21}$ & $x$ & $\sqrt{ }$ & \\
\hline & & 823 & 550 & 0.16 & 58.1 & 36.0 & $7.9 \times 10^{20}$ & $x$ & $\sqrt{ }$ & \\
\hline
\end{tabular}

Note: "Tirr" is the irradiation temperature; "-" means that information was given in the reference; " $\sqrt{ }$ ", observed; " $\times$ ", no observed.

These results indicate that hydrogen has an enhancement effect on the formation of the dislocation loop, especially on the loop growth. The diffusion of hydrogen atoms is definitely fast in the bcc metals. The migration energy of hydrogen in bcc metal is $0.01 \mathrm{eV}$ [34]. However, the hydrogen diffused in the material will be trapped by vacancy clusters and will form stable $\mathrm{H}-\mathrm{V}$ complexes [35]. The probability of recombination of the self-interstitials with the vacancies that are produced by hydrogen irradiation can be effectively reduced through the formation of $\mathrm{H}-\mathrm{V}$ complexes [36]. Compared with neutron and heavy ion irradiations, where most of the interstitials and vacancies produced by irradiation will recombine with each other, more interstitials survive under hydrogen irradiation and join in the growth of loops at the same damage level, thus promoting the growth of the dislocation loops.

\subsection{Burgers Vector Evolution of Dislocation Loop}

As shown in Figure $6 a$, the density ratio of the $\frac{1}{2} a_{0}<111>$ to $a_{0}<100>$ loops is about 9:10 at $523 \mathrm{~K}$. Upon heating to $623 \mathrm{~K}$ and above, only $\mathrm{a}_{0}<100>$ loops were observed. The early investigation of the molecular dynamics (MD) simulation found that all of the primary clusters induced by collision cascades in $\alpha$-Fe are $\frac{1}{2} \mathrm{a}_{0}<111>$ interstitial loops [37,38], and no $\mathrm{a}_{0}<100>$ interstitial loops were 
reported [39]. The work of Masters in 1963 provided the earliest observation of $\mathrm{a}_{0}<100>$ loops in iron irradiated with $\mathrm{Fe}^{+}$at $823 \mathrm{~K}$ [40]. Therefore, $\mathrm{a}_{0}<100>$ loops are considered to stem from $\frac{1}{2} \mathrm{a}_{0}$ $<111>$ loops [14]. However, the mechanisms of the formations of $\mathrm{a}_{0}<100>$ loops are still confused. A mechanism, that $\mathrm{a}_{0}<100>$ loops come from the transformations of $\frac{1}{2} \mathrm{a}_{0}<111>$ loops through the reaction $\frac{1}{2} \mathrm{a}_{0}[111]+\frac{1}{2} \mathrm{a}_{0}[1 \overline{11}] \rightarrow \mathrm{a}_{0}$ [100], was reported by Masters from experimental results [26], as well as by Marian et al. and $\mathrm{Xu}$ et al. from MD simulations [41,42]. While the research of Chen et al. provided another mechanism, that small $\mathrm{a}_{0}<100>$ loops can possibly come from the transformations of $\frac{1}{2} \mathrm{a}_{0}<111>$ loops directly, without the reaction [43].

Both of the mechanisms reported above indicate that the mobility of $\frac{1}{2} \mathrm{a}_{0}<111>$ loops may be a critical factor that determines the fraction of $\frac{1}{2} \mathrm{a}_{0}<111>$ transformed to $\mathrm{a}_{0}<100>$ loops in the irradiated specimens. Temperature is one of the significant factors affecting the mobility of $\frac{1}{2} \mathrm{a}_{0}<111>$ loops [44]. The mobility of $\frac{1}{2} \mathrm{a}_{0}<111>$ loops is increased at a high temperature, but is immobilized at a low temperature. Therefore, there should be a transition temperature that transforms dominated $\frac{1}{2} \mathrm{a}_{0}$ $<111>$ loops to only $\mathrm{a}_{0}<100>$ loops. The transition temperature is about $765 \mathrm{~K}$ in pure Fe [24], but is between $523 \mathrm{~K}$ and $623 \mathrm{~K}$ in Fe-9Cr alloys. The reason for this might be that, besides temperature, solute atom is also a significant factor affecting the transformation ratio of $\frac{1}{2} \mathrm{a}_{0}<111>$ to $\mathrm{a}_{0}<100>$ loops. Prokhodtseva et al. investigated pure $\mathrm{Fe}$ and $\mathrm{Fe}(\mathrm{Cr})$ alloys irradiated with $\mathrm{Fe}^{+}$at $0.05 \mathrm{dpa}$ at room temperature. They found that only the $\frac{1}{2} \mathrm{a}_{0}<111>$ loops were observed in pure $\mathrm{Fe}$, whereas a mixture of $\frac{1}{2} \mathrm{a}_{0}<111>$ and $\mathrm{a}_{0}<100>$ loops existed in the $\mathrm{Fe}(\mathrm{Cr})$ alloys. This result indicated that $\mathrm{Cr}$ favored the formation of $\mathrm{a}_{0}<100>$ loops [14]. Hence, the transition temperature should be dropped in the presence of $\mathrm{Cr}$ in Fe-based alloys. But the mobility mechanism of the $\frac{1}{2} \mathrm{a}_{0}<111>$ loop seems unfit for the $\mathrm{Fe}(\mathrm{Cr})$ alloys [44], because the mobility of the $\frac{1}{2} \mathrm{a}_{0}<111>$ loop decreased owing to the pinning effect of the loop by the added alloying element $\mathrm{Cr}$.

More interestingly, the present study shows that hydrogen favored the formation of $\mathrm{a}_{0}<100>$ loops. So far, reports concerning the key parameters (i.e., temperature and dose) for the transformation of $\frac{1}{2} \mathrm{a}_{0}<111>$ to $\mathrm{a}_{0}<100>$ loops in RAFM steel are limited. According to the investigation by Wakai et al., $\mathrm{a}_{0}<100>$ loops did not appear, and only $\frac{1}{2} \mathrm{a}_{0}<111>$ loops were observed after the F82H was irradiated by neutrons at $2.8 \mathrm{dpa}$ at a temperature of $523 \mathrm{~K}$, and $51 \mathrm{dpa}$ at $573 \mathrm{~K}$ [29]. While in the present study, after the RAFM steel specimen was irradiated by hydrogen to the very low dose of 0.16 dpa at $523 \mathrm{~K}$, more than half of the dislocation loops were observed to be the $\mathrm{a}_{0}<100>$ type (the density ratio of $\frac{1}{2} \mathrm{a}_{0}<111>$ to $\mathrm{a}_{0}<100>$ loops is about 9:10, as shown in Figure 6a). When the hydrogen irradiation temperature increased to $623 \mathrm{~K}$ and above at the same dose of $0.16 \mathrm{dpa}$, only $\mathrm{a}_{0}<100>$ loops were observed, while for the neutron irradiation of EUROFER 97 to the dose of $16.3 \mathrm{dpa}$, no $\mathrm{a}_{0}<100>$ loops were observed from 523 to $723 \mathrm{~K}$ [20]. Undoubtedly, the present study shows that the presence of hydrogen promoted the formation of $\mathrm{a}_{0}<100>$ loops, that is, hydrogen could reduce both the dose and temperature at which $\mathrm{a}_{0}<100>$ loops were formed. The mechanism needs further theoretical research from an atomic scale.

\section{Conclusions}

In present study, the evolutions of the dislocation loops that are dependent on irradiation temperature and fluence were investigated using TEM observations in RAFM steel irradiated by hydrogen ions. The main conclusions are summarized as follows:

1. The results of the elevated temperature irradiations indicate that there is an optimum temperature for dislocation loop growth and nucleation, which, in this work, is $723 \mathrm{~K}$. This is because of the differentiation of activation energy for migration between the self-interstitial and vacancy induced by hydrogen and the different chemical components of steels. The presence of hydrogen shifts the peak position of the size distribution of loops with temperature to the higher temperature.

2. Compared with the neutron and heavy ion irradiations at the same damage level, larger dislocation loops were observed in the hydrogen ion irradiation. A potential mechanism was given as follows: the probability of the recombination of self-interstitials with vacancies that 
are produced by hydrogen irradiation can be effectively reduced through the formation of $\mathrm{H}-\mathrm{V}$ complexes.

3. At an irradiation temperature of $523 \mathrm{~K}, 47.3 \% \frac{1}{2} \mathrm{a}_{0}<111>$ and $52.7 \% \mathrm{a}_{0}<100>$ loops were observed, but only $\mathrm{a}_{0}<100>$ loops were observed above $623 \mathrm{~K}$, when irradiated to $0.16 \mathrm{dpa}$. This can be explained by the mechanism where an elevated temperature favors the transformation of $\frac{1}{2} \mathrm{a}_{0}<111>$ to $\mathrm{a}_{0}<100>$ loops, and the irradiation ions of hydrogen and solute atoms, such as $\mathrm{Cr}$, might further promote the transformation. The presence of hydrogen promotes the formation of $\mathrm{a}_{0}<100>$ loops.

Author Contributions: Conceptualization, W.Z. and L.G.; data curation, Z.S., Y.L., X.Z., and C.C.; formal analysis, Z.S., Y.W., Y.L., X.Z., and C.C.; funding acquisition, L.G.; investigation, Y.W.; methodology, J.X. and Q.H.; resources, L.G., J.X., and Q.H.; supervision, L.G.; writing (original draft), W.Z.; writing (review and editing), L.G.

Funding: This research was funded by the National Natural Science Foundation of China (grant numbers 11775162 and U1532134) and the International Science \& Technology Cooperation Program of China (grant number 2015DFR60370).

Acknowledgments: The authors would like thank the Center for Electron Microscopy in Wuhan University, China.

Conflicts of Interest: The authors declare no conflict of interest.

\section{References}

1. Zinkle, S.J.; Was, G.S. Materials challenges in nuclear energy. Acta Mater. 2013, 61, 735-758. [CrossRef]

2. Kawai, M.; Kokawa, H.; Michiuchi, M.; Kurisihita, H.; Goto, T.; Futakawa, M.; Yoshiie, T.; Hasegawa, A.; Watanabe, S.; Yamamura, T.; et al. Present status of study on development of materials resistant to radiation and beam impact. J. Nucl. Mater. 2008, 377, 21-27. [CrossRef]

3. Ohshima, H.; Kubo, S. 5-sodium-cooled fast reactor. In Handbook of Generation IV Nuclear Reactors; Elsevier: New York, NY, USA, 2016; pp. 119-155.

4. Marian, J.; Hoang, T.; Fluss, M.; Hsiung, L.L. A review of helium-hydrogen synergistic effects in radiation damage observed in fusion energy steels and an interaction model to guide future understanding. J. Nucl. Mater. 2015, 462, 409-421. [CrossRef]

5. Klueh, R.L.; Gelles, D.S.; Jitsukawa, S.; Kimura, A.; Odette, G.R.; Van der Schaaf, B.; Victoria, M. Ferritic/martensitic steels-Overview of recent results. J. Nucl. Mater. 2002, 307-311, 455-465. [CrossRef]

6. Baluc, N.; Schäublin, R.; Spätig, P.; Victoria, M. On the potentiality of using ferritic/martensitic steels as structural materials for fusion reactors. Nucl. Fusion 2004, 44, 56-61. [CrossRef]

7. Kupriiyanova, Y.E.; Bryk, V.V.; Borodin, O.V.; Kalchenko, A.S.; Voyevodin, V.N.; Tolstolutskaya, G.D.; Garner, F.A. Use of double and triple-ion irradiation to study the influence of high levels of helium and hydrogen on void swelling of 8-12\% Cr ferritic-martensitic steels. J. Nucl. Mater. 2016, 468, 264-273. [CrossRef]

8. Zinkle, S.J. Challenges in developing materials for fusion technology-past, present and future. Fusion Sci. Technol. 2013, 64, 65-75. [CrossRef]

9. Wakai, E.; Kikuchi, K.; Yamamoto, S.; Aruga, T.; Ando, M.; Tanigawa, H.; Taguchi, T.; Sawai, T.; Oka, K.; Ohnuki, S. Swelling behavior of F82H steel irradiated by triple/dual ion beams. J. Nucl. Mater. 2003, 318, 267-273. [CrossRef]

10. Liu, C.; Klein, H.; Jung, P. Embrittlement of RAFM EUROFER97 by implanted hydrogen. J. Nucl. Mater. 2004, 335, 77-82. [CrossRef]

11. Farrell, K. Experimental effects of helium on cavity formation during irradiation-A review. Radiat. Eff. 1980, 53, 175-194. [CrossRef]

12. Heinisch, H.L.; Gao, F.; Kurtz, R.J. Atomic-scale modeling of interactions of helium, vacancies and helium-vacancy clusters with screw dislocations in alpha-iron. Philos. Mag. 2010, 90, 885-895. [CrossRef]

13. Brimbal, D.; Décamps, B.; Henry, J.; Meslin, E.; Barbu, A. Single- and dual-beam in situ irradiations of high-purity iron in a transmission electron microscope: Effects of heavy ion irradiation and helium injection. Acta Mater. 2014, 64, 391-401. [CrossRef]

14. Prokhodtseva, A.; Décamps, B.; Ramar, A.; Schäublin, R. Impact of He and $\mathrm{Cr}$ on defect accumulation in ion-irradiated ultrahigh-purity $\mathrm{Fe}(\mathrm{Cr})$ alloys. Acta Mater. 2013, 61, 6958-6971. [CrossRef] 
15. Tanaka, T.; Oka, K.; Ohnuki, S.; Yamashita, S.; Suda, T.; Watanabe, S.; Wakai, E. Synergistic effect of helium and hydrogen for defect evolution under multi-ion irradiation of Fe-Cr ferritic alloys. J. Nucl. Mater. 2004, 329-333, 294-298. [CrossRef]

16. Ando, M.; Tanigawa, H.; Jitsukawa, S.; Sawai, T.; Katoh, Y.; Kohyama, A.; Nakamura, K.; Takeuchi, H. Evaluation of hardening behaviour of ion irradiated reduced activation ferritic/martensitic steels by an ultra-micro-indentation technique. J. Nucl. Mater. 2002, 307-311, 260-265. [CrossRef]

17. Xiong, X.; Yang, F.; Zou, X.; Suo, J. Effect of twice quenching and tempering on the mechanical properties and microstructures of SCRAM steel for fusion application. J. Nucl. Mater. 2012, 430, 114-118. [CrossRef]

18. Standard Practice for Neutron Radiation Damage Simulation by Charged-Particle Irradiation, ASTM Designation E 521-89, Annual Book of ASTM Standards, vol. 12.02; American Society for Testing and Materials: Philadelphia, PA, USA, 1989; p. D-9.

19. Ehrhart, P.; Averback, R.S. Diffuse X-ray scattering studies of neutron- and electron-irradiated Ni, Cu and dilute alloys. Philos. Mag. A 1989, 60, 283-306. [CrossRef]

20. Klimenkov, M.; Materna-Morris, E.; Möslang, A. Characterization of radiation induced defects in EUROFER 97 after neutron irradiation. J. Nucl. Mater. 2011, 417, 124-126. [CrossRef]

21. Li, S.; Li, Y.; Lo, Y.C.; Neeraj, T.; Srinivasan, R.; Ding, X.; Sun, J.; Qi, L.; Gumbsch, P.; Li, J. The interaction of dislocations and hydrogen-vacancy complexes and its importance for deformation-induced proto nano-voids formation in $\alpha$-Fe. Int. J. Plast. 2015, 74, 175-191. [CrossRef]

22. Hashimoto, N.; Sakuraya, S.; Tanimoto, J.; Ohnuki, S. Effect of impurities on vacancy migration energy in Fe-based alloys. J. Nucl. Mater. 2014, 445, 224-226. [CrossRef]

23. Xu, S.; Yao, Z.; Jenkins, M.L. TEM characterisation of heavy-ion irradiation damage in FeCr alloys. J. Nucl. Mater. 2009, 386-388, 161-164. [CrossRef]

24. Yao, Z.; Jenkins, M.L.; Hernández-Mayoral, M.; Kirk, M.A. The temperature dependence of heavy-ion damage in iron: A microstructural transition at elevated temperatures. Philos. Mag. 2010, 90, 4623-4634. [CrossRef]

25. Jenkins, M.L.; Yao, Z.; Hernández-Mayoral, M.; Kirk, M.A. Dynamic observations of heavy-ion damage in Fe and Fe-Cr alloys. J. Nucl. Mater. 2009, 389, 197-202. [CrossRef]

26. Masters, B.C. Dislocation loops in irradiated iron. Philos. Mag. 1965, 11, 881-893. [CrossRef]

27. Huang, X.; Shen, Y.; Li, Q.; Xu, Z.; Zhu, J. Microstructural evolution of CLAM steel under $3.5 \mathrm{MeV} \mathrm{Fe}^{13+}$ ion irradiation. Fusion Eng. Des. 2016, 109-111, 1058-1066. [CrossRef]

28. Schäublin, R.; Victoria, M. Differences in the microstructure of the F82H ferritic / martensitic steel after proton and neutron irradiation. J. Nucl. Mater. 2000, 287, 339-343.

29. Wakai, E.; Miwa, Y.; Hashimoto, N.; Robertson, J.P.; Klueh, R.L.; Shiba, K.; Abiko, K.; Furuno, S.; Jitsukawa, S. Microstructural study of irradiated isotopically tailored F82H steel. J. Nucl. Mater. 2002, 307-311, $203-211$. [CrossRef]

30. Schaeublin, R.; Gelles, D.; Victoria, M. Microstructure of irradiated ferritic/martensitic steels in relation to mechanical properties. J. Nucl. Mater. 2002, 307-311, 197-202. [CrossRef]

31. Dethloff, C.; Gaganidze, E.; Aktaa, J. Microstructural defects in EUROFER 97 after different neutron irradiation conditions. Nucl. Mater. Energy 2016, 9, 471-475. [CrossRef]

32. Jia, X.; Dai, Y. Microstructure in martensitic steels T91 and F82H after irradiation in SINQ Target-3. J. Nucl. Mater. 2003, 318, 207-214. [CrossRef]

33. Little, E.A.; Bullough, R.; Wood, M.H. On the Swelling Resistance of Ferritic Steel. Proc. R. Soc. A Math. Phys. Eng. Sci. 1980, 372, 565-579. [CrossRef]

34. Kirsanov, V.V.; Musina, M.V.; Rybin, V.V. The influence of hydrogen on the formation of helium vacancy voids in metal. J. Nucl. Mater. 1992, 191-194, 1318-1322. [CrossRef]

35. Krom, A.H.M.; Bakker, A.D. Hydrogen trapping models in steel. Metall. Mater. Trans. B Process Metall. Mater. Process. Sci. 2000, 31, 1475-1482. [CrossRef]

36. Hayward, E.; Deo, C. Synergistic effects in hydrogen-helium bubbles. J. Phys. Condens. Matter 2012, 24, 265402. [CrossRef] [PubMed]

37. Bacon, D.J.; Gao, F.; Osetsky, Y.N. Primary damage state in fcc, bcc and hcp metals as seen in molecular dynamics simulations. J. Nucl. Mater. 2000, 276, 1-12. [CrossRef]

38. Stoller, R.E.; Odette, G.R.; Wirth, B.D. Primary damage formation in bcc iron. J. Nucl. Mater. 1997, 251, 49-60. [CrossRef] 
39. Terentyev, D.A.; Malerba, L.; Hou, M. Dimensionality of interstitial cluster motion in bcc-Fe. Phys. Rev. B Condens. Matter Mater. Phys. 2007, 75, 1-13. [CrossRef]

40. Masters, B.C. Dislocation loops in irradiated iron. Nature 1963, 200, 254. [CrossRef]

41. Marian, J.; Wirth, B.D.; Perlado, J.M. Mechanism of Formation and Growth of $<100>$ Interstitial Loops in Ferritic Materials. Phys. Rev. Lett. 2002, 88, 4. [CrossRef] [PubMed]

42. Xu, H.; Stoller, R.E.; Osetsky, Y.N.; Terentyev, D. Solving the puzzle of 100 Interstitial Loop Formation in bcc Iron. Phys. Rev. Lett. 2013, 110, 1-5. [CrossRef] [PubMed]

43. Chen, J.; Gao, N.; Jung, P.; Sauvage, T. A new mechanism of loop formation and transformation in bcc iron without dislocation reaction. J. Nucl. Mater. 2013, 441, 216-221. [CrossRef]

44. Schäublin, R.; Décamps, B.; Prokhodtseva, A.; Löffler, J.F. On the origin of the primary $\frac{1}{2} \mathrm{a}_{0}<111>$ and $\mathrm{a}_{0}$ $<100>$ loops in irradiated Fe(Cr) alloys. Acta Mater. 2017, 133, 427-439. [CrossRef]

(C) 2018 by the authors. Licensee MDPI, Basel, Switzerland. This article is an open access article distributed under the terms and conditions of the Creative Commons Attribution (CC BY) license (http:/ / creativecommons.org/licenses/by/4.0/). 